\title{
Determinants of Risky Sexual Behavior, Relation between HIV Risk Perception and Condom Utilization among Wollega University Students in Nekemte Town, Western Ethiopia
}

\author{
Elias Legesse Negeri* \\ Department of Public Health, College of Medical and Health Sciences, Post Box No: 395, \\ Wollega University, Nekemte, Ethiopia
}

\begin{abstract}
Students of Higher Education Institutions are assets of the society and change agents in filling the gap in the past and on whom the future generation is based. Neglecting their sexual and reproductive health can lead to high social and economic costs, both immediately and in the years ahead. This study tried to assess the determinants of risky sexual behavior, relation between HIV risk perception and condom utilization among University students in Western Ethiopia. The study was applied institution based cross-sectional study design triangulated with qualitative study. Multivariate logistic regression analysis with crude odds ratio was used. Partial correlation and linear regression was used to assess the applicability of Theory of Planned Behavior model in predicting intention to use condom and other variables. A pretested interviewer administered questionnaire was used to collect data. About $49.1 \%$ of students ever had sexual intercourse. Of these, $50.7 \%$ had their first sex before joining the university. Almost half $(50.2 \%)$ had two and more than two life time sexual partners. Having multiple sexual partners was significantly associated with consistent condom use [AOR=1.98; $95 \% \mathrm{Cl}: 1.63,2.94]$. About $46.1 \%$ thought that, they were at high risk of getting HIV infection and $61.3 \%$ reported consistent condom use with non-regular partner. In this study, Theory of Planned Behavior explained $39.3 \%$ of variances in intention to consistent condom use. This study has shown that, a substantial proportion of the students engaged in risky sexual. Information, education and communication/ behavioral change communication on risk perception, life, assertive and communication skills training and promotion of peer-education should be strengthened.
\end{abstract}

Copyright@2014 STAR Journal. All Rights Reserved.

\section{Article Information} Article History:

Received : 14-05-2014

Revised : 25-08-2014

Accepted : 27-08-2014

Keywords:

Condom Utilization

Risk Perception

Risky Sexual Behaviors

Theory of Planned Behavior

Wollega University

*Corresponding Author:

Elias Legesse Negeri

E-mail:

siifankoo@gmail.com

\section{INTRODUCTION}

An epidemiological synthesis exercise commissioned by HIV/AIDS Prevention and Control Office (HAPCO) and World Bank (WB) in 2007 indicated that, in recent years a number of new training and Higher Education Institutions (HEIs) have been opened in Ethiopia (FHAPCO, 2008). Students of HEls are assets of the society and change agents in filling the gap in the past and on whom the future generation is based. It is also clear that, this group is on the way of transforming to adulthood; filled with ambition; and building their future academic and social career (WHO, 2006).

HEls and their student populations have not been well studied (only very small amount has been explored), are often vulnerable to HIV infection, but there is some anecdotal evidences suggesting widespread unprotected sex (unsafe sexual practices), homosexual practices and anal sex which is known to be the most risky sexual behavior and hence face undesired health outcomes such as unplanned pregnancy, unsafe abortion, HIV/AIDS, college/university dropouts, Sexually Transmitted Infections (STIs), substance use and crime (WHO, 2006).
Many studies have shown that, HEls are a distinctive community where people interact, socialize and influence each other in terms of creating a shared identity, shared behavior including sexual behavior. The prevailing features of such shared behavior in to the surrounding communities and the result of such interaction and transaction in knowledge and experience has its own impact in the spread of HIV/AIDS (UNAIDS, 2008).

The most commonly used conceptual framework for studying the determinants of a particular behavior (Mollab, 2007) such as exercising, donating blood, adhering to a low-fat diet, using condoms for AIDS prevention, using illegal drugs, and wearing a safety helmet and others are better described by Theory of Planned Behavior (TPB) (Christopher, 2001). In the present study, the variable of perceived risk from the health-belief model was included because the high prevalence of HIV in Ethiopia might increase risk perception which in turn might affect the condom use. 


\section{Theory of Planned Behavior (TPB)}

The TPB, built upon the earlier Theory of Reasoned Action (TRA), focuses on the theoretical constructs that are concerned with individual motivational factors as determinants of the likelihood of performing a specific behavior. The central factor of the theory is the individual's intention to perform a given behavior. Intentions capture the motivational factors that influence behavior and are indications of how much of an effort people are willing to exert in order to perform a behavior. As a general rule, the stronger the intention to engage in a behavior, the more likely should be its performance. The TRA applies strictly to volitional behaviors, Ajzen and Madden proposed the TPB in order to account for nonvolitional behaviors (Ajzen et al., 1980; Ajzen et al., 1986; Bandura, 1986).

The theory predicts that the intention to perform a behavior is a function of three salient beliefs: the person's attitude, subjective norms and perceived behavioral control. The three predictors influence subsequent behavior indirectly through behavioral intention. The theory specifies that the determinants of attitudes, subjective norms and perceived behavioral control combine multiplicatively. One of the strengths of the Theory of Planned Behavior is its broad applicability. The theory has been able to account for a considerable proportion of the variance in intention and behavior in previous literature (Ajzen et al., 1980).

The TPB posits that behavioral intention is a function of attitude, reflecting a favorable or unfavorable evaluation of the particular behavior, subjective norm, referring to the perceived social pressure to perform the behavior. Perceived behavioral control reflects the ease or difficulty associated with performance and is closely related to the notion of self-efficacy (Ajzen, 1991). Attitudes, subjective norms and perceived behavioral control are underpinned by behavioral, normative and control beliefs respectively.

Attitudes have been the most widely researched aspect of the TPB and continue to receive attention from social and cognitive psychologists (Ajzen et al., 1980). Attitudes toward performing behavior reflect favorable or unfavorable evaluation of the particular behavior.

Attitude toward the behavior in this study case, consistent use of condom - is determined by individuals' beliefs about the outcome of performing the behavior (behavioral beliefs; belief that condom use is associated with certain attributes), weighed by the extent to which these outcomes are valued (belief outcomes; value attached to condom use).

Subjective norms refer to the perceived social pressure to perform the behavior. They are governed by perceptions of whether significant others think that one should perform the behavior (normative beliefs; belief about whether each referent approves or disproves of condom use) and one's motivation to comply with the wishes of significant others (motivation to comply; motivation to do what each referent thinks is right). With regard to norms, individuals differ in the weight they place on subjective norms as influencers; these also vary across behaviors (Ajzen et al., 1980). In other words, some adolescents may give importance to their attitude about the behavior when deciding to engage in a behavior, while other adolescents may give more importance to what they think others think they should do.

Perceived Behavioral Control (PBC) reflects the perceived ease or difficulty associated with behavior performance and with behavioral intention, and unlike attitudes or subjective norms, is posited to directly predict behavioral achievement. This construct of the theory is intended to account for situations where an individual has less than complete control over the behavior and includes two components. The first component is facilitating conditions which reflect the availability of resources needed to engage in a behavior. This might include access to the time, money and other resources required to engage in a behavior. The second component is selfefficacy and refers to the individual's self-confidence in his/her ability to perform a behavior (Ajzen, 1991).

Ajzen (1991) argues that a person will expend more effort to perform a behavior when his or her perception of behavioral control is high. Beliefs about the presence of factors that might hinder the behavioral achievement (control beliefs; perceived likelihood of occurrence of each facilitating/constraining condition) and perceived ability to control factors that might hinder the behavioral achievement (power of control; perceived effect of each condition in condom use difficulty/easy) provide the basis for perceived behavioral control.

According to the theory, an individual's intention to perform a specific behavior is a direct determinant of whether he or she will act. To accurately assess the behavior, one must take into account the target, time, context and behavior on which the intent is being judged (Ajzen et al., 1986). The theory's validity is therefore achieved through empirical support for the relationships among attitudes, subjective norms, perceived behavioral control and their relative path weights that lead to intention.

The most commonly used conceptual framework for studying the determinants of a particular behavior (Warner, 2004) such as exercising, donating blood, adhering to a low-fat diet, using condoms for AIDS prevention, using illegal drugs, and wearing a safety helmet and others are better described by theory of planned behavior (Mollab et al., 2007). Nowadays, many of sexual behavior literature are based on Ajzen's TPB, which suggests that behavior is planned, rational and intentional.

In the present study, the variable of perceived risk from the health-belief model was included because the high prevalence of HIV in Ethiopia might increase risk perception which in turn might affect the condom use.

According to TPB, human behavior is guided by three kinds of considerations:

1. Beliefs about the likely outcomes of the behavior and the evaluations of these outcomes (behavioral beliefs),

2. Beliefs about the normative expectations of others and motivation to comply with these expectations (normative beliefs) and

3. Beliefs about the presence of factors that may facilitate or impede performance of the behavior and the perceived power of these factors (control beliefs) 


\section{Elias Legesse Negeri}

In their respective aggregates, behavioral beliefs produce a favorable or unfavorable attitude toward the behavior; normative beliefs result in perceived social pressure or subjective norm; and control beliefs give rise to perceived behavioral control. In combination, attitude toward the behavior, subjective norm, and perception of behavioral control lead to the formation of a behavioral intention [Christopher et al., 2001). A study done in rural Ethiopian population shows that, the TPB explains $36 \%$ of the variance of intention to condom use (Fekadu et al., 2001). The UK Meta analytic study shows a little higher $39 \%$ intention variance (Renfroe, 1990).
Sci. Technol. Arts Res. J., July-Sep 2014, 3(3): 75-86

Another study done among Ethiopian female adolescents on contraceptive use shows that $29 \%$ of the variance in intention to use contraceptives (Ross et al., 1991). Attitude and subjective norm explained $46.1 \%$ of the intention in a study done on documentation behavior of nurse's (Tlou, 2009).

A research done on homosexually active men using TRA shows that the subjective norm was better predictor of intention to use condom than attitude (Bennett et al., 200)] but studies done in South Africa on TRA/TPB in a work place HIV/AIDS health promotion program, attitude was the most significant predictors followed by PBC (Alamerew et al., 2013).

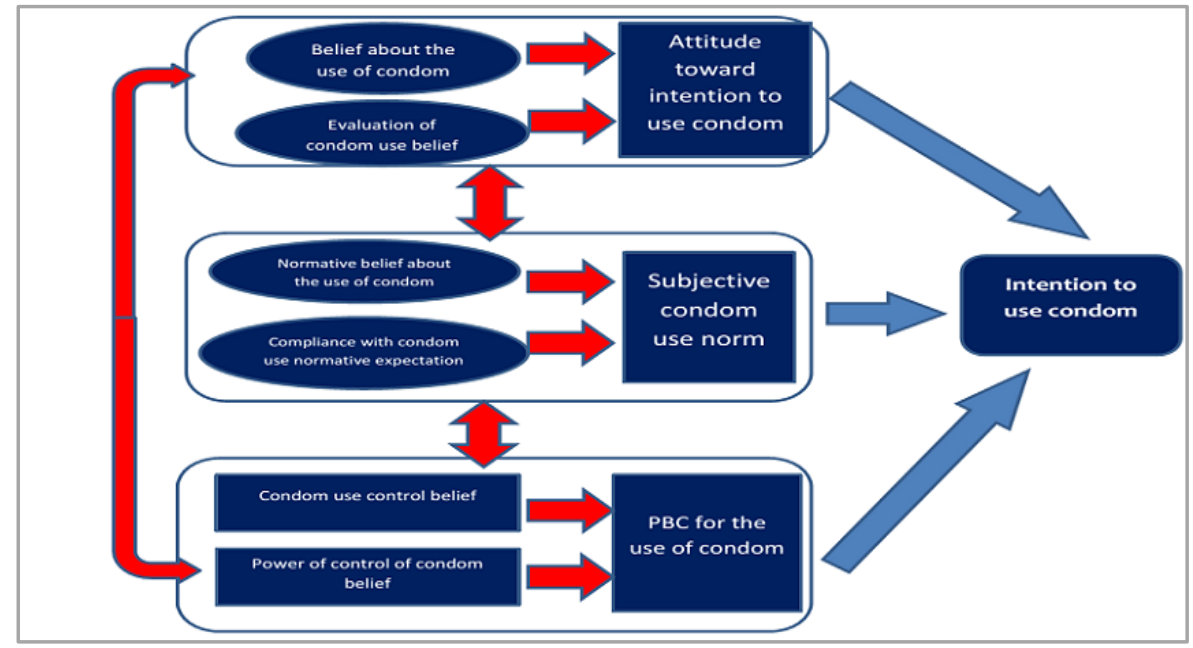

Figure 1: Theory of planned behavior constructs (Adapted from Ajzen, 1991)

The reason why we should focus on this group is that, they are future parents and if intervention, be it educational or otherwise, brings about cultural and behavioral changes in them, and then surely they influence the practices of the next generation, and many more after.

Consequently, this study was conducted with the intention of filling the aforementioned research gaps by pinpointing risky sexual behaviors and predisposing factors for possible interventions.

\section{MATERIALS AND METHODS}

\section{Study Design and Area}

The study was applied institution based crosssectional quantitative study design triangulated with qualitative study (Focus Group Discussions (FGDs) and In-Depth Interview (IDI)) in the study area from April 01 to 30, 2013.The study was conducted in Wollega University (Nekemte, Gimbi and Shambo campuses), Western Ethiopia.

\section{Sample Size}

The sample size for the quantitative survey was computed using a formula for calculating single population proportions, with $95 \%$ confidence level and $5 \%$ level of accuracy. Sample size was calculated considering the proportion of inconsistent condom use with non-regular partner in the last 12 months among students of Jimma University (30.9\%) was taken as high risk behavior indicator (Tura et al., 2012). The study was considered $15 \%$ non-response rate and design effect of 2 . The calculated total sample size was 883 students.

\section{Sampling Techniques}

Prior to the study, identification of the number of campuses, colleges, schools and number of students in each campus were checked from university registrar record office by the principal investigator. Initially, students were divided into Wollega University Nekemte main campus, Gimbi and Shambu campuses. Then, they were further stratified based on the year of study and department. Systematic sampling technique was applied to select individuals from the total strata in the university in each year of study from the list of students' name in their respective batch. Then, the total sample size was allocated to each department proportional to the number of students in the department.

In order to ensure gender equity, both female and male participants from each campus took part in the study. For purposes of convenience and anonymity, participants who showed interest in the study were proposed to approach the researchers to be a part of the FGDs. Eight FGD sessions (made up of 5 to 7 members in each group) were carried out based on level of information saturation. In addition to FGDs, 10 IDIs were conducted with students' service director, students' union president, gender office, students' clinic head, Marie Stopes International Ethiopia- Nekemte branch, university anti-AIDS movement leaders and members and counselors at the respective campuses. This was also to ensure that information received takes into account the perspectives of service providers and young people since they are the potential sex educators and socializing agents. 


\section{Data Collection}

A quantitative data was collected using intervieweradministered questionnaire. The questionnaire was prepared originally in English and then translated to Afan Oromo and Amharic languages and back retranslated to English to check its consistency. The selected students were interviewed at their convenient time and place.

In this study qualitative research was used to complement the quantitative study and the data was collected by trained and experienced facilitators. Focus Group Discussions were made using guiding questions followed by anticipated probing questions in quite class rooms and female's group were moderated by female moderator while, that of males' group was moderated by male moderator and research assistants. Notes were taken and recorded by using tape recorder.

\section{Data Processing, Analysis and Quality Management}

The questionnaire was checked for completeness and consistency by the principal investigator. Data obtained from the questionnaires were entered, cleaned and prepared for tabulation using SPSS software version 20. The results were illustrated in the form of frequency tables and depicted graphically in order to give a quick glance of the variables. Multivariate logistic regression analysis was used to see the net effects of each independent variable in explaining variation in the outcome variables and the strength of association was expressed in odds ratio (OR) and its $95 \%$ confidence interval $(95 \% \mathrm{Cl})$.

Partial correlation and linear regression was used to assess the applicability of TPB model in predicting intention to use condom and other variables. Cronbach's reliability test (alpha coefficient) was used to check the internal consistency of the constructs of TPB. Each and every variable for the model was measured with the help of a five point likert scale ranging from strongly agree to strongly disagree.

Pre-testing of the questionnaire was conducted on samples of students and or youths of similar sociodemographic background taken from Ambo and Jimma Universities. Research assistants, supervisors and data collectors were trained on how to conduct interview. The collected data was reviewed and checked for completeness before data entry. Five percent of the data was double-entered in order to compare and assure the quality of the data.

Qualitative data was initially written out, translated to English by playing back the tape recorder and the data were analyzed by arranging the issues put forward at the time of group discussion independently i.e. thematic analysis was used to generate themes. This method of analysis is used to identify, analyze and report patterns within data as well as interpreting various aspects of the research topic (Netsanet et al., 2012). The students who are selected for FGDs were excluded from the quantitative part of the study.

\section{Measurements}

Sexual Risk Behavior: according to this study it is defined as: unprotected sex (inconsistent use of condoms), having multiple sexual partner, starting sex before age of 18 years and sex with commercial sex workers.
Substance Use: use of at least any one of the following substances: alcohol, khat cigarette, shisha, hashish or drug that are assumed to affect level of thinking and increase risk of involving in risky sexual behavior.

Non-regular Partner: sexual partner out of marital union.

Consistent Condom Use: using condom during or at every sexual encounter.

HIV Risk Perception: students' attitude towards perceiving themselves as susceptible to HIV infection.

Intention to Use Condom: the respondents' plan to use condom in the next three months of sexual intercourse to avert their chances of HIV infection. It was measured by three items of intention to use condom with a response ranged from $1=$ not likely at all to $5=$ very likely. Each item was summed and its score was between 3 and 15 . The intention formation was strong for higher intention score.

Belief about the Use of Condom: the extent to which an individual think the advantage of using condom. It was measured by four items of assessing their thought on consistent condom use with a response ranged from likert scale of $1=$ strongly disagree to $5=$ strongly agree. Each item was summed and was between a score of 4 to 20 . The higher the sum scores the more favorable belief it is to use condom consistently.

Evaluation of Condom Use Belief: the students' evaluation of the salient consequence resulted from using condom in the next three months. It was measured by four items of evaluating the consequences of the above beliefs with a response ranged from likert scale of $1=$ extremely undesirable to $5=$ extremely desirable. Sum of each item was between 4 and 20 score and shows the higher the number, the more chance of positive evaluation.

Attitude towards the Use of Condom: students' predisposition to respond in favorable (positive) or unfavorable (negative) manner towards the use of condom. It was composed from items of the behavioral belief and outcome evaluation. According to the TPB, attitude score is derived from the multiplication of each behavioral belief items with their corresponding outcome evaluation.

Normative Belief towards Condom Use: the perception held by students whether significant others think that $\mathrm{s} / \mathrm{he}$ should use the condom. It was constructed by five item with a response ranged from likert scale of $1=$ strongly disagree to $5=$ strongly agree. A sum score was made and ranges 5-25. The higher the sum scores, the more perception of respondents on referents others thinking on condom use.

Motivation to Comply of Normative Beliefs: the students' motivation to comply with the specific referents wishes about using condom. It was made by five items correspondence with normative belief items with a response range from likert scale $1=$ strongly disagree to $5=$ strongly agree. A sum score of the items was made and ranges 5 to 25 .

Subjective Norm of Condom Use: the students' perception that significant others think him/her to use condom as a normative action. It is composed from items 


\section{Elias Legesse Negeri}

of the normative belief and motivation to comply. According to the TPB, subjective norm score was derived from the multiplication of each normative belief items with their corresponding motivation to comply items.

Condom Use Control Belief: belief about the presence of factors that might hinder or facilitate the use of condom. It was measured by 4 items with a response of likert scale $1=$ very unlikely to $5=$ very likely. Sum score was calculated by adding each items and the range was 4 to 20 .

Power of Control of Condom Use Belief: perceived control ability of individuals to control factor that might hinder the use of condom in the coming three months. It was measured by four items with a response of likert scale $1=$ completely uncertain to $5=$ completely certain. Sum score was calculated by adding each items and the range was between 4 and 20 .

Perceived Control for the Use of Condom (Perceived Behavioral Control): the perceived easy or difficulty associated with the use of condom. It is composed from items of the control belief strength and control belief power. According to the TPB, perceived behavioral control score was derived from the multiplication of each control belief strength items with their corresponding control belief power items.

Perceived Risk: Respondents was first asked to rate the possibility of becoming HIV infected in the future. They will also be asked to indicate the extent to which they agreed that AIDS is a dangerous disease in general, in Ethiopia, in their communities, among students of the same college/university, and to themselves. All responses with respect to perceived risk ranged from $1=$ strongly agree to $5=$ strongly disagree. Items PR was reverse-coded and summed with PR to create a scale of perceived risk, such that higher scores indicated more perceived risk of HIV/AIDS.

Past Experience with Condom Use: the respondents were first asked whether they have used condoms in the past when having sex with casual/regular partner during the last three months. It was measured by two items: Have you ever used condom? And have you used condom when having sex with a casual partner? Response categories (1) yes always, (2) yes but not always, and (3) No. The two items was added and dichotomized for the purpose of analyses into (1) experienced with condom use and (2) not experienced with condom use.

Self-reported use of condom: it was assessed using two items. Example: "How often have you used condom when having sexual intercourse with partner during the previous three months?" Scale: $1=$ all the time to $5=$ never.

\section{Ethical Consideration}

Ethical clearance was obtained from Research Ethics Review Committee of Wollega University, and the research was done in conformity with the ethical guidelines approved by the Research Ethics Review Committee (RERC) of Wollega University. Supporting letter was written by Wollega University to other campuses of the university to get institutional consent after communicating with formal letters and to other relevant concerned bodies to get official permission.
Sci. Technol. Arts Res. J., July-Sep 2014, 3(3): 75-86

Respondents were informed about the objective and purpose of the study. Participation in the study was completely voluntary and refusal to respond to some of the questions or interruption from the study was possible at any time the respondent need.

All the information obtained from the respondent was remained confidential and anonymous by using code numbers (as an alternative of names) and proper storage of all forms of information and documents to keep away from the access to individuals other than principal investigator(s). Written consent was attached to each questionnaire (for both qualitative and quantitative approaches) and was read out by the interviewer at the time of data collection. All participants were signed on the written consents form provided after completing the questionnaire. Prior to interview of each study participant both verbal and written consent procedures were approved by Research Ethics Review Committee of Wollega University.

\section{RESULTS}

\section{Descriptive Findings}

The socio-demographic features of the study participants' is shown in Table 1. From the total of 883 students, 563 males and 297 females participated in the survey making the response rate of $97.4 \%$. Therefore, 860 completed questionnaires included in the analysis. Majority, $712(80.6 \%)$ of the respondents were between the age range of $20-24$ years, $86(9.7 \%)$ of them were between 15 to 19 years. The mean $( \pm S D)$ age of all students was $21.2( \pm 1.7)$ and $20.6( \pm 1.9)$ years for males and females respectively.

\section{Sexual Behaviors of the Respondents}

Sexual behaviors of the study participants' is shown in Table 2. Out of the total respondents, almost half, $422(49.1 \%)$ of students ever had sexual intercourse. Disaggregated by sex, 205(48.6\%) of males and $217(51.4 \%)$ of females had had sex. The overall mean and median age of sexual debut for both sexes was $17.2(+2.15)$ and 18 years respectively. The mean age of sexual debut was $17.5( \pm 2.21)$ and $16.9( \pm 3.10)$ years overall for males and females respectively. The finding from FGD discussants also stated that, early sexual activity (before the age of 18 ) is widely practiced.

A 22 years old male respondent stated that, "...sexual intercourse should be started after marriage and if possible after graduating from the university and guaranteeing their own income at least in order to overcome the problems attached with the sexual activity."

From the 422 sexually experienced respondents (who ever had sexual intercourse), 214(50.7\%) had their first sex before joining the university and $208(49.3 \%)$ of the respondents after joining the university. The study revealed that, 393(93.1\%) students had sex in the last 12 months; of these $185(47.1 \%$ ) males and $208(52.9 \%)$ females. Almost half, $212(50.2 \%)$ of students reported that, they had two and more than two lifetime sexual partners and of which, $142(67.2 \%)$ and $70(32.8 \%)$ males and females respectively.

More than one fourth of the sexually experienced students, 111(26.3\%) had their first sex with their casual partner, $27(6.4 \%)$ benefit based partner and 284(67.3\%) had their first sex with their permanent partner. In the 
Table 1: Percentage distribution of socio-demographic characteristics of undergraduate Wollega University students who participated in the study, Nekemte, Western Ethiopia, 2013

\begin{tabular}{|c|c|c|c|}
\hline \multirow{2}{*}{ Characteristics } & \multicolumn{3}{|c|}{ Number (percentage) } \\
\hline & Male $(n=563)$ & Female $(n=297)$ & Total $(\mathrm{N}=860)$ \\
\hline \multicolumn{4}{|l|}{ Religion } \\
\hline Orthodox & 216(38.3) & $119(40.1)$ & $335(34.9)$ \\
\hline Protestant & $176(31.2)$ & 99(33.4) & $275(31.1)$ \\
\hline Muslim & $113(20.1)$ & $69(23.1)$ & $182(20.6)$ \\
\hline Others $^{*}$ & $59(10.4)$ & $10(3.4)$ & $69(7.8)$ \\
\hline \multicolumn{4}{|l|}{ High school attended } \\
\hline Public high school & $476(84.5)$ & $253(85.3)$ & $729(82.5)$ \\
\hline Private high school & 64(11.4) & $30(10.1)$ & $94(10.6)$ \\
\hline Missionary high school & $23(4.1)$ & 14(4.6) & $37(4.1)$ \\
\hline \multicolumn{4}{|l|}{ Self-reported academic performance } \\
\hline Below average (2.00) & $81(14.3)$ & $64(21.5)$ & $145(16.4)$ \\
\hline At least average (2.00) & $396(70.3)$ & 193(65.0) & $589(66.7)$ \\
\hline Top ten & 104(18.4) & $40(13.5)$ & 144(16.3) \\
\hline \multicolumn{4}{|l|}{ Ethnicity } \\
\hline Oromo & $296(52.7)$ & $153(51.5)$ & $475(53.7)$ \\
\hline Amhara & $158(28.1)$ & $90(30.0)$ & $253(28.6)$ \\
\hline Tigre & $52(9.2)$ & $24(8.2)$ & $76(8.6)$ \\
\hline Gurage & $34(6.0)$ & $21(7.2)$ & $55(6.2)$ \\
\hline Others ${ }^{\star *}$ & $23(4.0)$ & $9(3.1)$ & $32(3.7)$ \\
\hline \multicolumn{4}{|l|}{ Study year } \\
\hline Year one & $222(39.5)$ & $126(42.4)$ & $348(40.4)$ \\
\hline Year two & $164(29.2)$ & $85(28.5)$ & $249(28.9)$ \\
\hline Year three & $119(24.1)$ & $69(23.3)$ & $188(21.8)$ \\
\hline Year four and above $e^{\star * *}$ & $41(7.2)$ & $17(5.8)$ & $58(6.7)$ \\
\hline \multicolumn{4}{|l|}{ Current place of accommodation } \\
\hline Dormitory (in campus) & $515(91.4)$ & 282(95.1) & $797(90.2)$ \\
\hline Outside campus (rented house and with family) & $48(8.6)$ & $15(4.9)$ & $63(7.1)$ \\
\hline \multicolumn{4}{|l|}{ Previous place of residence } \\
\hline Urban & $176(31.2)$ & $70(23.6)$ & $246(28.7)$ \\
\hline Semi-urban ${ }^{1}$ & $144(25.6)$ & $86(28.6)$ & $230(26.7)$ \\
\hline Rural $^{2}$ & $248(44.0)$ & $136(45.9)$ & $384(44.6)$ \\
\hline \multicolumn{4}{|l|}{ Pocket money from parents/relatives (birr/month) } \\
\hline$<200$ birr per month & $313(55.6)$ & $138(46.4)$ & $451(52.4)$ \\
\hline 200-500 birr per month & $170(30.2)$ & $120(40.5)$ & $290(33.7)$ \\
\hline$>500$ birr per month & $80(14.2)$ & $39(13.1)$ & $119(13.8)$ \\
\hline \multicolumn{4}{|l|}{ Perceived family economic status } \\
\hline Poor & $120(21.3)$ & $71(23.9)$ & $191(22.2)$ \\
\hline Medium & $400(71.1)$ & $197(66.4)$ & $597(69.4)$ \\
\hline Rich & $43(7.6)$ & $30(10.1)$ & $73(8.4)$ \\
\hline \multicolumn{4}{|c|}{ Religiosity (Frequency of visiting church or mosques) } \\
\hline Never attend & $59(10.4)$ & 13(4.2) & $72(8.3)$ \\
\hline Attend frequently & $339(60.3)$ & $207(69.8)$ & $546(63.4)$ \\
\hline Occasionally & 165(29.3) & $77(26.0)$ & 242(28.1) \\
\hline \multicolumn{4}{|c|}{$\begin{array}{l}{ }^{*} \text { Catholic, Wakefata (traditional), Adventist, No Religion (pagan); }{ }^{* *} \text { Gambella, Benishangul Gumuz, Wolayita, } \\
\text { Somali, Afar, Sidama; }{ }^{* * *} \text { Year four and above (Year IV, V and VI). } \\
{ }^{1} \text { Regional and zonal capitals, }{ }^{2} \text { Woreda and other towns }\end{array}$} \\
\hline
\end{tabular}

finding from FGDs, most of the students enlightened as some of the students had sex for the sake of benefits including academic as well as economic advantages.

More than three fourth, $330(78.1 \%)$ of sexually active study participants (who ever had sexual intercourse) never used condoms in their first sex encounter. In this study, 295(75\%) of those who had sexual intercourse had used condom during their last sexual contact. However, consistent condom use with non-regular sexual partner in the last 12 months was 51.5 and $24.8 \%$ with regular sexual partner.

This study revealed that, odds of sexual experience among students living outside the campus in rented house were almost two times higher than those living in campus (AOR=1.95; 95\%Cl: 1.86, 5.28). Those who reported as scoring at least average (2.00 CGPA) were 1.66 times to ever have sex as compared to those reported to be found in top ten from their class in academic achievement (AOR=1.66; 95\%Cl: 1.93, 3.31) (Table 3).

The findings of this study revealed that, students who were attending religious institutions occasionally or sometimes were about four times at risk to have multiple sexual partners (AOR=3.73; 95\%Cl: $1.57,8.85)$ compared to students who attend religious institutions frequently. As FGD participants explained, the greater frequency of attending religious institutions is related with fewer numbers of sexual partners, where religiousness (greater attachment to religion) appears to be a protective factor against much number of sexual partners. 
Table 2: Sexual behaviours (activity) of undergraduate Wollega University students, Nekemte, Western Ethiopia, 2013

\begin{tabular}{|c|c|c|c|}
\hline \multirow{2}{*}{ Characteristics } & \multicolumn{3}{|c|}{ Number (\%) } \\
\hline & Male $(n=563)$ & Female $(\mathrm{n}=297)$ & Total $(\mathrm{N}=860)$ \\
\hline \multicolumn{4}{|c|}{ Age of first sexual intercourse $(n=422)$} \\
\hline$<15$ years & $22(32.8)$ & $46(67.2)$ & $68(16.2)$ \\
\hline $15-19$ years & $86(47.2)$ & $96(52.3)$ & $182(43.2)$ \\
\hline $20-24$ years & $112(65.4)$ & $60(34.6)$ & $172(40.6)$ \\
\hline \multicolumn{4}{|c|}{ Used condom in the first sex $(n=422)$} \\
\hline Yes & $55(60.3)$ & $37(39.7)$ & $92(21.9)$ \\
\hline No & $134(40.5)$ & 196(59.5) & $330(78.1)$ \\
\hline \multicolumn{4}{|c|}{ Condom utilization in the last 12 months $(n=393)$} \\
\hline Never used & $6(10.4)$ & $51(89.6)$ & $57(13.4)$ \\
\hline Sometimes & $17(15.2)$ & $94(84.8)$ & $111(26.3)$ \\
\hline Always (consistent) & $195(75.4)$ & $14(24.6)$ & $259(61.3)$ \\
\hline \multicolumn{4}{|l|}{ Having best friend experienced sex } \\
\hline Yes & 238(42.3) & $171(57.7)$ & 409(47.5) \\
\hline No & $183(32.5)$ & $198(67.5)$ & $381(44.3)$ \\
\hline \multicolumn{4}{|c|}{ Reasons not to use condom $(n=330)^{\star \star}$} \\
\hline I don't trust condom & $7(49.4)$ & $8(50.6)$ & $15(4.5)$ \\
\hline Not accessible & $4(44.7)$ & $5(55.3)$ & $9(2.8)$ \\
\hline Partner objected & $23(55.3)$ & $27(54.7)$ & $50(15.1)$ \\
\hline Embarrassed to buy & $52(15.9)$ & $27(8.2)$ & $79(23.9)$ \\
\hline I trust my partner & $32(38.7)$ & $52(61.3)$ & $84(25.5)$ \\
\hline Decreases pleasure or satisfaction & $82(47.5)$ & $90(52.5)$ & $172(52.1)$ \\
\hline \multicolumn{4}{|c|}{ Age of sexual partner during first $\operatorname{sex}(n=422)$} \\
\hline Same age & $87(42.3)$ & $46(21.2)$ & $133(31.5)$ \\
\hline More than 10 years older than me & $12(6.0)$ & $57(26.3)$ & $69(16.3)$ \\
\hline $5-10$ years older than me & $17(8.5)$ & $87(40.3)$ & $104(24.6)$ \\
\hline Less than 5 years older than me & $11(5.3)$ & $26(12.0)$ & $37(8.7)$ \\
\hline Younger than me & $77(37.6)$ & $3(1.2)$ & $80(18.9)$ \\
\hline \multicolumn{4}{|c|}{ Number of pregnancy (females only) $(n=208)$} \\
\hline Never been pregnant & NA & $170(79.6)$ & $170(79.6)$ \\
\hline One or more & NA & $38(18.4)$ & $38(18.4)$ \\
\hline \multicolumn{4}{|l|}{ Outcome of pregnancy $(n=38)$} \\
\hline Gave live birth & NA & $6(16.5)$ & $6(16.5)$ \\
\hline End in abortion & NA & $32(83.5)$ & $32(83.5)$ \\
\hline \multicolumn{4}{|l|}{ History of STI symptoms $(n=422)$} \\
\hline Yes & $25(12.3)$ & $23(10.6)$ & $48(11.3)$ \\
\hline No & $180(87.7)$ & $194(894)$ & $374(88.7)$ \\
\hline
\end{tabular}

In this study, males were more likely to have multiple sexual partners as compared to female students. Males were 1.96 times more likely to have multiple sexual partners compared to females $(\mathrm{AOR}=1.96,95 \% \mathrm{Cl}: 1.29$, 6.21).

This study further acknowledged that, getting pocket money from parents or relatives greater than 500 ETB per month and being in the age group of 20-24 years was significantly associated with having multiple sexual partnerships.

The students who get pocket money more than 500ETB per month were almost two times at risk of having multiple sexual partnerships when compared to those who get less than 200 ETB per month $(A O R=1.87$; $95 \% \mathrm{Cl}: 1.53,5.25)$ and who are in the age group of $20-24$ years were 1.45 times at risk of having multiple sexual partnerships than those who are found in the age group of 15-19 (AOR=1.45; 95\%Cl: $1.84,4.88)$.

Males were about three times more likely to use condom consistently as compared to female respondents (AOR=3.33; 95\%Cl: 1.59, 4.42). The students who have two and greater than two sexual partners two times more likely to use condom consistently than students with one sexual partner $(\mathrm{AOR}=1.98 ; 95 \% \mathrm{Cl}: 1.63,2.94)$.
Youths who drink alcohol were about two times more likely to use condom inconsistently as compared to those who don't drink (AOR=2.03; 95\% $\mathrm{Cl}: 1.48,3.87)$. The odds of using condom consistently is significantly two times higher for youths who don't perceive risk of HIV infection than who perceive $(\mathrm{AOR}=2.26 ; 95 \% \mathrm{Cl}: 1.48,5.94)$.

FGD participants also revealed that, the advantages pertaining to consistent use of condom. They have indicated that, it protect students from having unwanted pregnancy which further do have a paramount impact on health if it ends up with abortion, and HIV infection. A 20 years old female respondent said that, “...I don't trust condoms' prevention capacity $100 \%$, but, I will use it if I have sex with a person other than my regular partner. At least it will help me to lessen or minimize being fear of getting STIs including HIVIAIDS, risk of unwanted pregnancy."

The odds of having had sex is significantly three times higher for youths drinking alcohol than youths who didn't drink (AOR=2.94; 95\% Cl: 1.24, 3.04); while students who chew khat were 1.6 times more likely than non-chewers (COR=1.60; 95\% Cl: 1.13, 3.27). 
Table 3: Factors associated with sexual initiation among under graduate Wollega University students Nekemte, Western Ethiopia, 2013

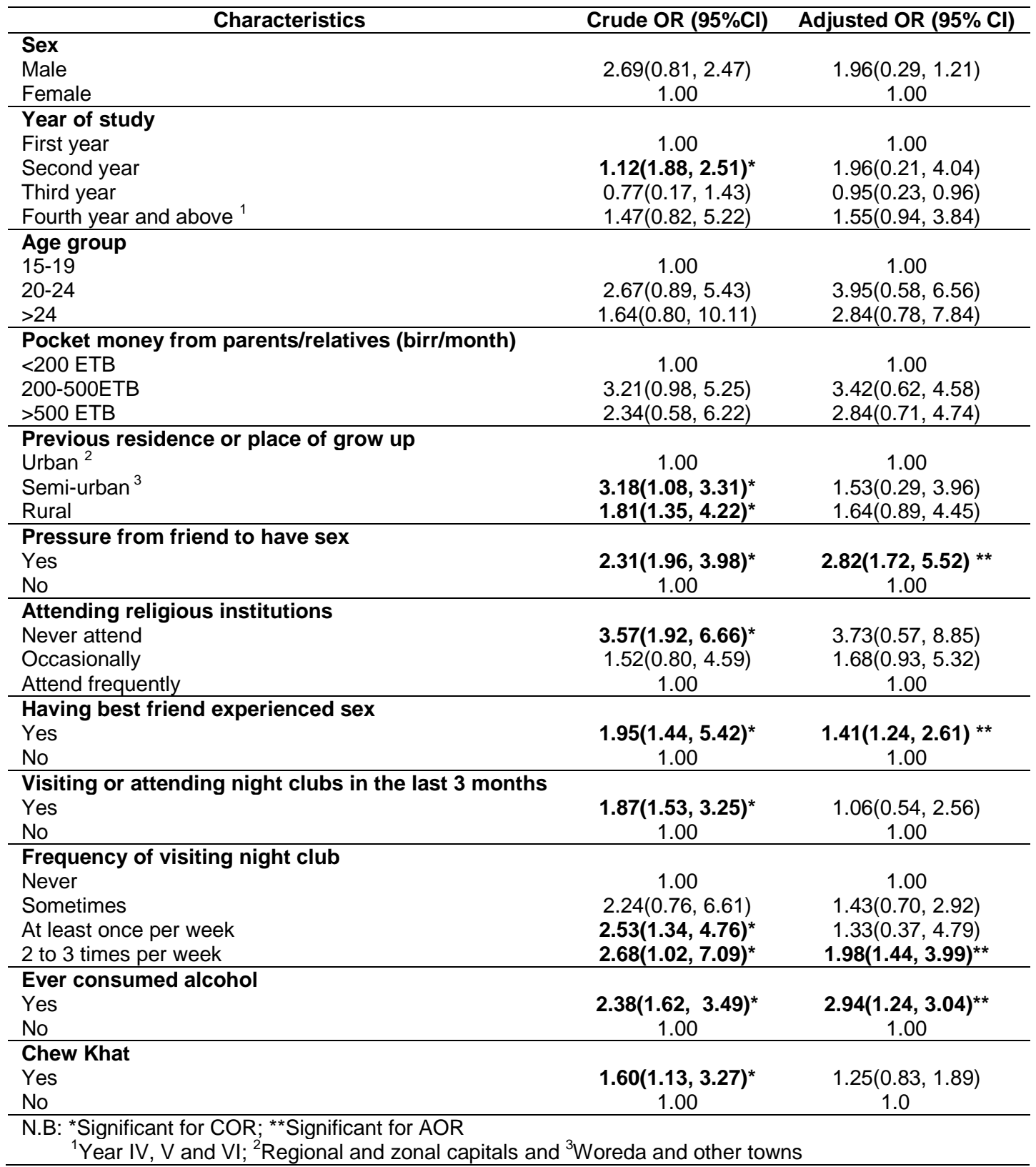

\section{Risk Perception of Youths}

In the present study, study participants were asked whether they were perceived themselves as susceptible to HIV infection or not and about $396(46.1 \%)$ of youths thought that they were at high risk of getting HIV infection, while $217(25.2 \%)$ said there was no chance at all and the remaining $247(28.7 \%)$ did not know their risk status (Table 4).

\section{Theory of Planned Behavior Constructs}

As far as the intention of the students on consistent condom use was concerned, 563(65.5\%) of them had showed good intention of it. Nearly two third of the students, $528(61.4 \%)$ of the youths have developed good attitude toward the intention of consistent condom use. Regarding social pressure, $484(56.3 \%)$ of the participants were given high value to social pressure in order to have more intention to use condom and $581(67.6 \%)$ of the participants perceived easy for intention to consistent condom use.
This current study illustrates that, the partial correlation coefficient of attitude toward the intention of consistent condom use, subjective norm of condom use, perceived behavioral control, study year, average pocket money per month and condom use history.

Intention to consistent condom use was significantly and positively correlated with each of the constructs of TPB among males and females. Female students had more good (positive) attitude toward condom use than their male counter parts $(r=0.64, P<0.01)$ for females and $(r=0.52, P<0.01)$ for males]. Among the constructs of TPB, calculated Pearson's correlation between subjective norm for the entire sample and behavioral intention was the maximum $(\mathrm{r}=0.67, \quad P<0.001)$; followed by perceived behavioral control $(r=0.49, P<0.001$ and attitude $(r=0.43$, $P<0.001$ ) (Table 5). 
Table 4: Selected characteristics (predictor variables) on youths own risk perception among undergraduate Wollega University students, Nekemte, Western Ethiopia, 2013

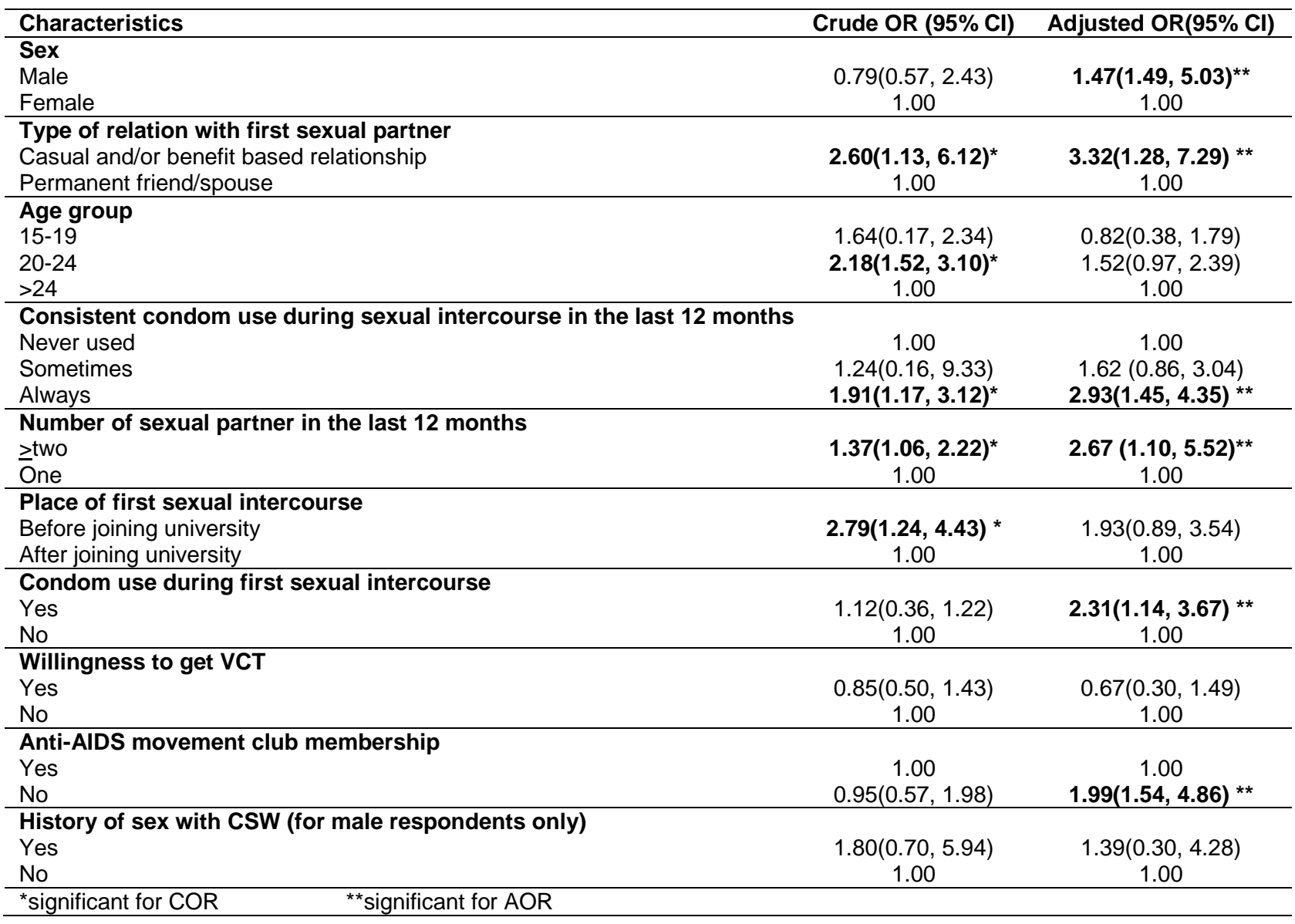

Table 5: Partial correlation of the components of TPB and other variables among undergraduate Wollega University students, Nekemte, Western Ethiopia, 2013

\begin{tabular}{|c|c|c|c|c|c|c|}
\hline Variables & Attitude & SN & PBC & $\begin{array}{c}\text { Average } \\
\text { Pocket } \\
\text { Money }\end{array}$ & $\begin{array}{c}\text { Condom } \\
\text { Use } \\
\text { History }\end{array}$ & $\begin{array}{c}\text { Intention to } \\
\text { Condom } \\
\text { Use }\end{array}$ \\
\hline \multicolumn{7}{|l|}{ Total $(n=860)$} \\
\hline Attitude & 0.986 & & & & & \\
\hline Subjective norm of condom use (SN) & $0.543^{\star *}$ & 0.69 & & & & \\
\hline Perceived Behavioral Control (PBC) & $-0.041^{*}$ & $0.001^{* *}$ & 0.71 & & & \\
\hline Average pocket money per month & $0.056^{*}$ & -0.368 & -0.073 & & & \\
\hline Condom use history in any sexual intercourse & 0.361 & 0.514 & -0.096 & 0.006 & & \\
\hline Intention to consistent condom use & $0.514^{\star *}$ & $0.552^{* *}$ & $0.052^{* *}$ & 0.035 & 0.033 & 0.88 \\
\hline Mean & 82.62 & 82.2 & 71.1 & & & 6.8 \\
\hline Standard Deviation (SD) & 20.53 & 27.3 & 24.7 & & & 2.2 \\
\hline
\end{tabular}

Significant at ${ }^{* *} P<0.001,{ }^{*} P<0.05$, controlled for age, year of study, sex, previous residence, religion and current place of accommodation, Internal consistency reliability (alpha coefficient) is presented in the diagonal for each TPB constructs

In the present study, positive Pearson's correlation among the variables stated above signifies that, behavioral intentions of the youths to use condom consistently in the next three months was enhanced by increments of TPB constructs. The average pocket money per month was negatively correlated with intention to use condom consistently.

As it was indicated in table 5, all the sociodemographic variables (age, sex, year of study, previous residence, religion and current place of accommodation) were entered in the first step of analysis and it explains $5.6 \%$ of the variance in intention to use condom consistently. Subsequently, each constructs of TPB were entered independently in the second step of analysis and in combination in third step of analysis. Hence, the largest variance of intention to use condom consistently was explained by subjective norms (35.1\%) and followed by attitude $(21.1 \%)$ and perceived behavioral control (15.3\%) among males and females.

The three main components are all significant in explaining the variance of the dependent variable behavioral intention with subjective norm explaining more of the variance than attitude and perceived behavioral control toward the behavior being the least predictor of the variance.

The three predictor of the TPB (subjective norm, perceived behavioral control and attitude) explain $60.2 \%$ 


\section{Elias Legesse Negeri}

of the total variance of behavioral intention. But, attitude and subjective norm explained only $40.6 \%$ of the variance in intention to use condom.

The relationship between socio-demographic characteristics and TPB constructs was tabulated with the intention to use condom among male and female students. In the multiple regression model, the strongest
Sci. Technol. Arts Res. J., July-Sep 2014, 3(3): 75-86

predictor of intention to consistent condom use was perceived behavioral control $(\beta=0.428, P<0.000)$ followed by subjective norm $(\beta=0.363, \quad P<0.000)$ and attitude $(\beta=0.284, P<0.001)$ in descending order. Nevertheless, in the simple linear regression, the most strong predictor was subjective norm $(\beta=0.595, P<0.000)$ as of the attitude $(\beta=0.462, P<0.000)$ and perceived behavioral control was $(\beta=0.398, P<0.000)$ (Table 6).

Table 6: Linear regression analysis for socio-demographic variables and TPB constructs among undergraduate Wollega University students with intention to consistent condom use, Nekemte, Western Ethiopia, 2013

\begin{tabular}{|c|c|c|c|c|c|c|c|c|c|}
\hline \multirow{2}{*}{ Variables } & \multirow[b]{2}{*}{$\mathbf{R}$} & \multirow[b]{2}{*}{$\mathbf{R}^{2}$} & \multirow{2}{*}{$\begin{array}{l}\text { Adj. } \\
\mathbf{R}^{2}\end{array}$} & \multirow{2}{*}{$\begin{array}{c}\mathbf{R}^{2} \\
\text { change }\end{array}$} & \multirow{2}{*}{$\begin{array}{c}\mathbf{F} \\
\text { change }\end{array}$} & \multirow{2}{*}{$\begin{array}{c}P \text { - } \\
\text { value }\end{array}$} & \multicolumn{3}{|c|}{ Standard $\beta$ Coefficient } \\
\hline & & & & & & & $\beta \mathbf{A}$ & $\beta S N$ & BPBC \\
\hline Socio-demographic variables ${ }^{\#}$ & 0.368 & 0.135 & 0.133 & 0.135 & 23.149 & $0.000^{*}$ & & & \\
\hline Attitude & 0.462 & 0.213 & 0.211 & 0.213 & 42.234 & $0.000^{*}$ & $0.462^{*}$ & & \\
\hline Subjective norm of condom use (SN) & 0.595 & 0.354 & 0.351 & 0.354 & 51.496 & $0.000^{*}$ & & $0.595^{*}$ & \\
\hline Perceived Behavioural Control (PBC) & 0.398 & 0.158 & 0.153 & 0.158 & 63.685 & $0.000^{*}$ & & & $0.398^{*}$ \\
\hline Attitude + Subjective Norm & 0.642 & 0.412 & 0.406 & 0.067 & 15.599 & $0.000^{*}$ & $0.395^{*}$ & $0.572^{*}$ & \\
\hline Attitude + Subjective Norm + PBC & 0.784 & 0.614 & 0.602 & 0.048 & 10.196 & $0.001^{*}$ & $0.284^{*}$ & $0.363^{*}$ & $0.428^{*}$ \\
\hline
\end{tabular}

\section{DISCUSSION}

This study attempted to provide important information on determinants of risky sexual behavior, relation between HIV risk perception and condom utilization among University students and has been seen comprehensively (both quantitatively and qualitatively) and also the study tried to find out intention to use condom among Wollega University students using constructs of Theory of Planned Behavior.

This current study illustrates that, out of the total respondents, $49.1 \%$ of students ever had sexual intercourse. Disaggregated by sex, $48.6 \%$ of males and $51.4 \%$ of females had had sex. In contrast, this finding is very much higher than the study done in Dire Dawa University, 30\% (Mollaab et al., 2007). The figure in this study is almost similar when compared with the results of similar studies in Bahirdar city which was $50.7 \%$, and studies done in Southern Ethiopia where the figure was $49 \%$ for both sexes (Alamerew et al., 2013; Zerai, 2002). There was also a similar finding in a study done at Gonder University (Legesse et al., 2006), though the proportion reported here is a little lower.

This study showed that, from the total sexually experienced respondents, $50.7 \%$ had their first sex before joining the university and $49.3 \%$ of the respondents after joining the university. Similarly in study conducted among undergraduate University students of Ethiopia, more than three fourth, (77.2\%) started sexual intercourse before they joined university. The issue of early sexual initiation is a problem not only at university level, but also at high school level. This might suggest that intervention should start before students join the university either being in primary second cycle or secondary schools (Dingeta et al., 2012). However, in this study almost half of the students started sexual activity after coming to the university such condition should be given much emphasis.

The mean and median age of sexual initiation was $17.2( \pm 2.15)$ and 18 years overall respectively. This study was comparable with other similar studies done among youths of Wolaita Sodo and Jimma University (Gelibo et al., 2013; CSA, 2012). This is almost similar with the findings of the Ethiopian Demographic Health Survey
2011(EDHS 2011) in which the median age at first sexual intercourse among 20-24 years were 18.8 years. This study was also comparable with the studies conducted in Nepal and Nigeria (Okafar, 2005; Adhikari et al., 2009) indicating that most students initiated sexual activity during adolescence. These indicate the need for effective sex education for students in Ethiopia and elsewhere at an early age, probably in their high school years (Dingeta et al., 2012).

Almost half, $50.2 \%$ of students reported that they had two and more than two lifetime sexual partners. This finding is considerably by far greater than the study done among undergraduate university students in Ethiopia, 24.5\% and Jimma University, 28.9\% (Dingeta et al., 2012; CSA, 2012).

The study further pointed out that, only $53.8 \%$ of the respondents had used condom in their first sexual intercourse. Better usage was observed when compared with the result of similar studies in Debre Birhan and Dire Dawa Universities in which $46.6 \%$ and $33.6 \%$ of sexually active study participants never used condoms respectively, which is in agreement with what has been reported from earlier studies in Ethiopia (Mollaab et al., 2007; CSA, 2012).

In this study, $75.6 \%$ of those who had sexual intercourse in the last 12 months had used condom during the last sexual contact. This is slightly lower than a study conducted in Jimma University (80\%), in this study condom use rate among sexually active students (55.6\%) and the finding of EDHS 2011 (47\% for male and $62 \%$ for female youths) (Tura et al., 2012; CSA, 2012).

Our study further identifies that, males were more likely to use condom consistently as compared to female respondents, $73.5 \%$ and $46.4 \%$ respectively. About $80 \%$ of males used condom during their last sexual encounter. This fact was consistent with a number of other studies done in different parts of the country (Tura et al, 2012; CSA, 2012; Mitike et al, 2005). This could be explained by the fact that, females' inability and lack of empowerment to negotiate condom use due to socio-economic conditions (for instance sex in exchange of benefit) of the sexual encounter, gender and cultural norms in Ethiopia 


\section{Elias Legesse Negeri}

(Tura et al., 2012; Soet et al., 1998). Peer (male sexual partner) pressure, also results in diminished participation of females in decision making regarding condom use, as compared to males, again due to gender and cultural norms in Ethiopia (Desalegn et al., 2012). This high reported condom use by males was may also be due to social desirability bias.

If consistent condom use remains low, vulnerable sexual networks and practices will continue among the students, allowing for the faster spread of sexually transmitted infections including HIV/AIDS. These findings therefore highlight very high vulnerabilities among university students and calls for more rigorous prevention and awareness creation campaigns (Dingeta et al., 2012).

Concerning the participants' risk perception of HIV/AIDS, $46.1 \%$ of youths thought that, they were at high risk of HIV infection, while $25.2 \%$ said there was no chance at all and the remaining $28.7 \%$ did not know their risk status. This study was analogous with the findings of other studies conducted among Nigerian University students in which few students identified themselves to be at high risk even though majority of them (92\%) were sexually experienced (Harding et al., 1999).

In the present study, the TPB explained $39.3 \%$ of variances in intention to consistent condom use which is almost similar with a study done in UK which explains $39.0 \%$ variation of the intention (Chistopher et al., 2001) and slightly greater than study conducted in rural Ethiopian population which was $36.0 \%$ of the variance in intended condom use (Mollaab et al., 2007).

This current study illustrates that; intention to consistent condom use was significantly and positively correlated with each constructs of TPB students (among both males and females). Amongst the constructs, subjective norm was the principal and positively correlated variable with maximum correlation coefficient $(r=0.67$, $P<0.001)$ followed by perceived behavioral control $(\mathrm{r}=0.49, P<0.001$ and attitude $(\mathrm{r}=0.43, P<0.001)$. This finding is in line with a study done among adolescents in Uganda (Koenig et al., 2004).

From this one can deduce that, each and every variable has a contribution in explaining the disparities in intention to consistent condom use and further signifies policy makers and programmers to make area of focus as intention is the proximal determining factor of behavior in order to have the desired outcome of the behavior i.e. consistent condom use.

The result of this study indicated that, the strongest positive predictor of intention to use condom based on simple linear regression was subjective norm (which is influenced by normative belief and motivation to comply) about condom use which was in line with a study conducted among teachers of Harari region (Omer et al., 2010). When we see the multiple linear regression of the constructs, the most strong predictor of intention to use condom was perceived behavioral control $(b=0.284 ; p<=$ 0.001 ) other constructs were similar in strength of sequence like simple linear regression. Most importantly these figures explain that, interventions to improve intention to use condom should targeted on improving of relevant other's people belief and the total set of accessible control belief on condom use are useful than
Sci. Technol. Arts Res. J., July-Sep 2014, 3(3): 75-86

planning to attempt alteration of behavioral beliefs about, and attitudes toward condoms use in more focus.

Other studies done in South Africa on TRA/TPB in a work place HIV/AIDS health promotion program, intention to use condom strength was explained in terms of standardized regression coefficient and it shows that attitude was the most significant predictor followed by perceived behavioral control (Tlou et al., 2009). This might be because of the setting and the intended intention difference between the two studies. Additionally, sociodemographic variables were also included in the linear regression and explained $5.6 \%$ of the variance in intention to use condom. Therefore, including of these variables would have also importance in elevating the desired intention.

The strength of this study lies in its ability to involve a large sample size with an excellent response rate. The major limitation of the study was its sensitivity as it dealt with personal lives of university students. Secondly it is expected to be prone for the limitation of cross-sectional survey (Temporal relationship).

\section{CONCLUSIONS}

This study has shown that, a substantial proportion of the students engaged in different risky sexual behaviors that are evidenced by the existence of multiple sexual partners and sexual practice without condom with nonregular partner that predispose the students to STIs including HIV infection and unwanted pregnancy. Strengthening IEC/BCC on risk perception, life, assertive and communication skills training, promoting peereducation, designing and implementing awareness rising and risk reduction activities to put knowledge in to practice, availing necessary services including condom and working together with all stakeholders.

\section{ACKNOWLEDGEMENTS}

I would like to acknowledge the Student Service Directorate office of Wollega University at Nekemte, Gimbi and Shambu campuses for their full cooperation and facilitation of the actual data collection. My appreciation also goes to the supervisors, data collectors and all the respondents who generously and willingly participate in the study, without them this study would have been unthinkable.

\section{REFERENCES}

Adhikari, R. and Tamang, J. (2009). Premarital sexual behavior among male college students of Kathmandu, Nepal. BMC Public Health 9: 241.

Alamrew, Z., Bedimo, M and Azage, M. (2013). Risky Sexual Practices and Associated Factors for HIV/AIDS Infection among Private College Students in Bahir Dar City, Northwest Ethiopia. Journal of ISRN Public Health 1-9.

Ajzen, I. and Fishbein, M (1980). Understanding attitudes and predicting social behaviour. Englewood Cliffs, NJ: Prentice Hall.

Ajzen, I. and Madden, T.J. (1986). Prediction of goal directed behaviour: attitudes, intentions and perceived behavioural control. Journal of Experimental Social Psychology 22: 453-474.

Ajzen, I. (1991). The Theory of Planned Behaviour. Organizational Behaviour and Human Decision Processes 50(2): 179-211. 


\section{Elias Legesse Negeri}

Bandura, A. (1986). Social foundations and thoughts of action: A social cognitive theory. Englewood Cliffs, $\mathrm{NJ}$ : Prentice Hall.

Bennett, P. and Bozionelos, G. (2000). The theory of planned behaviour as predictor of condom use: anarrative review. Psychology, Health and Medicine 5(3):308-326.

Central Statistical Agency (2012). Demographic and Health Survey 2011. Addis Ababa, Ethiopia. ICF International, Calverton, Maryland, USA. 189-244.

Christopher J. Armitage. and Conner, M. (2001). Efficacy of the Theory of Planned Behavior: A Meta analytic review. British Journal of Social Psychology 40: 471-99.

Dessalegn, M. and Wagnew, M. (2012). Predictors of consistent condom use among University students: Hierarchical analysis, Debre Berhan, Ethiopia. Global Journal of Medicine and Public Health 1(4): 23-28.

Dingeta, T., Oljira, L. and Assefa, N. (2012). Patterns of sexual risk behavior among undergraduate university students in Ethiopia: a cross-sectional study. The Pan African Medical Journal 12:33.

Fekadu, Z. and Kraft, P. (2001). Predicting Intended Contraception in a sample of Ethiopian Female Adolescents: The Validity of the Theory of Planned Behaviour. Journal of Psychology and Health 16: 207-22.

FHAPCO (2008). Report on progress towards implementation of the UN declaration of commitment on HIV/AIDS, HIV/AIDS in Ethiopia: An Epidemiological Synthesis; Addis Ababa, Ethiopia.

Gelibo, T., Belachew, T. and Tilahun, T. (2013). Predictors of sexual abstinence among Wolaita Sodo University Students, South Ethiopia. Reproductive Health 10:18.

Harding, A., Anadu, E., Gray, L.A. and Champeau, D. (1999) Nigerian university student's knowledge, perceptions, and behaviors about HIV/AIDS: Are these students at risk? Journal of the Royal Society of Health 119(1):23-31.

Koenig, M.A., Zablotska, I., Lutalo, T., Nalugoda, F., Wagman, J. and Gray, R. (2004). Coerced first intercourse and reproductive health among adolescent women in Rakai, Uganda. International Family Planning Perspectives 30(4):156-163.

Legesse, B. and Davey, G. (2006). Intention to use condoms and remaining faithful in students at Gondar University. Ethiopian Public Health Association 1-54.

Mitike, G., Tesfaye, M. and Ayele, R. (2005) HIV/AIDS behavioral surveillance survey (BSS). Addis Ababa: Ethiopian Ministry of Health (MOH) and HIV/AIDS Prevention and Control Office (HAPCO); Addis Ababa, Ethiopia. BSS/MOH/HAPCO.
Sci. Technol. Arts Res. J., July-Sep 2014, 3(3): 75-86

Mollaab, M., Nordrehaug, A. and Brehane, Y. (2007). Applicability of the theory of planned behaviour to intended and self-reported condom use in a rural Ethiopian population. AIDS Care: Psychological and Socio-medical Aspects of HIVIAIDS 19(3): 425-31.

Netsanet, F., Tsion, A., Fessahaye, A. and Fentie, A. (2012). Parents' perception, students' and teachers' attitude towards school sex education. Ethiopian Journal of Health Sciences 22(2): 99-106.

Okafor, II and Obi, S.N. (2005). Sexual risk behavior among undergraduate students in Enugu, Nigeria. Journal of Obstetrics and Gynecology 25(6): 592-5.

Omer, S. and Haidar, J. (2010). Applicability of the theory of planned behavior in predicting intended use of Voluntary HIV Counselling and Testing services among teachers of Harari Region, Ethiopia. Ethiopian Journal of Health Development 24(2): 98-101.

Renfroe, D.H., O'Sullivan, S. and McGee, G.W. (1990). The relationship of attitude, subjective norm, and behavioural intent to the documentation behaviour of nurses. Scho Inq Nursing Practice 4(1):47-64.

Ross, W.M. and McLaws, L.M. (1991) Subjective norms about condoms are better predictors of use and intention to use than attitudes. Health Education journal 7(3): 335339.

Soet, J.E., Dilori, C and Dudley, W.N. (1998). Women's selfreported condom use: intra and interpersonal factors. Journal of Women and Health 27:19-32

Tlou, R.E. (2009). The application of the theory of reasoned action and planned behavior to a work place HIV/AIDS health promotion programme: University of South Africa, 164-190.

Tura, G., Alemseged, F. and Dejene, S. (2012) Risky Sexual Behavior and Predisposing Factors among Students of Jimma University, Ethiopia. Ethiopian Journal of Health Science 22:170-180.

UNAIDS (2008). Preventing HIV/AIDS in Young People: A Systematic Review of the Evidence Global HIV/AIDS Epidemic. 14(6).

Warner, P. (2004). Reasoned Action and Planned Behaviour Theories: Application to Nursing Research Philadelphia.

WHO (2006). Investing in our future: A framework for accelerating action for the sexual and reproductive health of the young people; Geneva, Switzerland.

Zerai, K. (2002). Sexual Experiences and their Correlates among Jimma University Students, Jimma, Ethiopia. Ethiopian Journal of Health Sciences 15(1):21-29. 